\title{
Towards a Development Strategy for the Recruitment and Retention of Women Seafarers in Cargo Ships with Particular Reference to the Republic of Korea
}

\author{
+ Sohyun, JO \\ †Full Time Lecturer, Division of International Education Team, \\ Korea Institute of Maritime and Fisheries Technology, Busan 608-829, Republic. of Korea
}

\begin{abstract}
The prime objective set for paper is to identify what are the women seafarers' problems and concerns regarding employment on cargo ships. From the cargo ship point of view, the question then is how to provide sufficient solutions for women seafarers in the male-dominated workplace of the ship through Corporate Social Responsibility(CSR) activities. The methodologies of study combine qualitative and quantitative research methods. The progress of research is to conduct a survey by asking a consistent set of key opinion leaders from the Republic of Korea. Moreover, to evaluate the elements of the result, the research explores the way in which we should consider giving priority to aspects of the problem. Finally, based on the terms of CSR, the author recommends measures to support the needs of women when they are employed onboard the world's merchant vessels.
\end{abstract}

Key words : Women seafarers, Corporate Social Responsibility(CSR), Gender issues, Working Environment, Women Empowering, Sexual discrimination

\section{Introduction}

Women seafarer numbers are increasing in the world's fleets in the position of officers, ratings and pilots in many types of ship such as cruise ships, bulk carriers and tankers. According to a recent study, Belcher, P., Sampson H., Thomas M., Veiga J., and Zhao M.(2003), women represent only 1-2 percent of the 1.25 million seafarers in the world. Moreover, the study indicates that 94 percent of women are employed on passenger ship and 6 percent are employed on cargo ships.

However, despite the slight increase of women seafarers working onboard, there are few studies concerning women seafarers indicating that there has been insufficient progress especially on cargo ships(Kitada, 2009a). In addition, the author has been researching and investigating these studies regarding women seafarers, however, most of these studies focus on passenger ships or cruise ships, not cargo ships. It is difficult to find relevant studies regarding women seafarers in the world, including in Republic of Korea (here after refer to Korea).

In the case of Korea, despite women being aboard ship since 1995, all aspects of the study of Korean women seafarers has not sufficiently addressed policies on how to women seafarers onboard. Few existing studies are available so far regarding reality for many women who work onboard on cargo ships. Possibly it is natural that these studies focus on male or overall seafarers rather than women seafarers because women coming onboard in just a few past years as a pioneer step and occupy 1-2 percent among all the seafarers of the world.

The prime objective set for this study is to identify what women seafarers' problems are and concerns employment on cargo ships. The cargo ship point of view, the question then is how to provide solutions for women seafarers in the male-dominated workplace(Aggrey, 2000) of the ship through Corporate Social Responsibility(CSR) activities. Therefore, it is worth noting overwhelmingly that to achieve this change dynamic, there is a need for attitudinizing change towards recruiting women as seafarers. Such changes, if implemented, might also attract more women seafaring career.

Further, Women are an underutilized and available resource of maritime talent which the shipping sector needs to draw the balance upon to seafarer's shortfall(ILO, 2007). Thus, it might be worthwhile to conduct some solutions and policies concerning the recruitment and retention of women into the seafarer labour market in Korea; as well as promote plans for women seafarers in the future.

\subsection{Methodology}

Therefore, to achieve the full objective of this study it is

† Corresponding author, calmseas0905@yahoo.co.kr, 051)620-5806 
intended to address the main issues surrounding the recruitment and retention of women seafarers in Korea, while providing some analysis of women seafarers' statistics or/and databases. The methodologies of study combine qualitative and quantitative research methods. The progress of research is to conduct a survey by asking some a consistent set of key opinion leaders from Korea.

Through telephone and questions, in-depth interviews were used as the major means of research according to individual participant preference. Although the response of questionnaires and data were only collected from a limited number of seafarers, these individuals were carefully selected with the view of considerable experience at sea. With this result, the author conducted a Frequency Analysis and Cross Tabs Analysis on respondents of the sample questionnaires through a Statistical package for social sciences.

\section{Women seafarers' historiography in the shipping industry}

\subsection{Participation of women seafarers in the world}

The study reviewed the history of women seafarers in the world has existed over long period. According to Belcher et al.(2003), in the post-1945 period women began to appear regularly as crew members aboard cargo ships, most often on Swedish ships as stewardesses, cooks and radio officers. In the late $1960 \mathrm{~s}$, a significant event was the first women that were recruited as officer cadets and this was mainly in response to the shortfall of male seafarers in Europe. It could be noted these instances may have been seen as pioneering steps, yet the fact remains that companies still preferred to hire male seafarers. From the mid-1980s, the shipping industry lessened this interest in recruiting women because of an overcapacity problem with a new source of male seafarers from Asia and Europe. In the late 1990s, when the industry began to experience more serious difficulties in recruiting men as seafarers, attention did again return to the recruitment of women. since the late 1990s, there has been a growing interest in training and recruiting women seafarers. This is largely connected to the perceived shortages of officers in the world fleets, including Korea.

\subsection{Participation of women seafarers in Korea}

The new policy for education was to allow female students to enter the Korea College of Maritime Sciences of
Korean Maritime University(KMU) that was a maledominated institution for men until 1991. This new policy was based on changing social trends and the needs to give an opportunity for high quality education to future workers. Further the new government policy wanted to improve and develop gender equality. Consequently, one female student entered the KMU in 1991 and graduated in 1995 as the first woman Navigation Officer( $3^{\text {rd }}$ class $)$ in Korea.

\subsection{Breaking the all male-tradition in the maritime sector}

As previously mentioned, the KMU was opened to female students' in 1991 and, since then, the five female students graduated from the University in 1995, and contributed by working onboard as deck officers or engineer officers in major shipping companies. The female seafarers have been a significant starting point for women by encouraging and installing confidence in them so they were able to go to sea as equal seafarers in a male dominated environment. They have broken the all-male tradition which was a place perceivably off-limits to females. Unsurprisingly, this of course was considered a significant social issue and came to the forefront in the Korean media. The subject of women seafarers in Korea as well in the global sense is no longer a new one.

Thereafter, female students have continued to graduate from the KMU and also the Mokpo Maritime University (MMU). The total number of female students at the KMU and the MMU are 887 women till 2010.

In the case of KMU, the total number of graduated female students is 464 today according to Table 1. Further female admission was limited to 10 percent of the students entering the Korea College of Maritime Sciences among 400 students total capacity per year under the entrance regulation policy. However, under a more recent entrance regulation policy it has currently admitted up to 15 percent females from the total number of students as well as the MMU(Kim, 2008)

Further, there are similar examples of low female participation in global marine and nautical schools or Institutions, where the ratio of male to female students represented is 95:5 in the Netherlands and 96:4 in both Germany and the United Kingdom(Belcher et al., 2003).

According to the study by Belcher et al.(2003), it is observed that the proportion of enrolled female students among MET institutions in 2001 averages 10.8 percent females against the total number of students among 13 MET Institution1). In fact, its data includes the crucial 
meaning that the participation of females in MET institutions is at a low level in general.

Table 1 Status of graduated University female

\begin{tabular}{|c|c|c|c|c|}
\hline Year & $\begin{array}{c}\text { Male } \\
\text { students }\end{array}$ & $\begin{array}{c}\text { Women } \\
\text { students }\end{array}$ & $\%$ & Total \\
\hline 1995 & 341 & 1 & 0.3 & 342 \\
\hline 1996 & 376 & 5 & 1.3 & 381 \\
\hline 1997 & 364 & 6 & 1.6 & 370 \\
\hline 1998 & 354 & 16 & 4.5 & 370 \\
\hline 1999 & 355 & 23 & 6.5 & 378 \\
\hline 2000 & 332 & 33 & 9.9 & 365 \\
\hline 2001 & 301 & 49 & 16.3 & 350 \\
\hline 2002 & 351 & 48 & 13.7 & 399 \\
\hline 2003 & 334 & 20 & 6.0 & 354 \\
\hline 2004 & 351 & 21 & 6.0 & 372 \\
\hline 2005 & 329 & 20 & 6.1 & 349 \\
\hline 2006 & 352 & 30 & 8.5 & 382 \\
\hline 2007 & 314 & 30 & 9.6 & 344 \\
\hline 2008 & 322 & 57 & 17.7 & 379 \\
\hline 2009 & 321 & 56 & 17.4 & 377 \\
\hline 2010 & 346 & 49 & 14.2 & 395 \\
\hline Total & 5443 & 464 & 8.5 & 5907 \\
\hline
\end{tabular}

Source : Korea Maritime University(2010)

\section{The trend of women seafarers' employment}

\subsection{Current women seafarers' occupation in the world}

According to Belcher et al.(2003) study, it has been estimated that women represent only 1 to 2 percent of the world's 1.25 million seafarers and that most of these women are from developed countries. Thus, the largest number of women is found working as hotel staff of passenger ships, particularly on cruise ships and ferries.

As shown in the following figure 1, according to Belcher et al.(2003) based on the SIRC/ILO Survey, it is found that the great majority of the world's women seafarers (94 percent) are employed aboard passenger ships which ferries and cruise ships as officers as well as ratings. The 2003's study above indicated that 68 percent of all the women $(3,554)$ work on ferries, overwhelmingly the highest number, and 26 percent on cruise ships with just small

1) 13 MET institutions: FNB(Spain), SMU(China), CIAGA(Brazil), ITUMF(Turkey), AMA(Belgium), TUMM(Japan), FMST (Slovenia), ENMM(France), SMS(Sweden), CMU(Romania), SIMA(Denmark), ENIDH(Portugal), GCMS(United Kingdom), Source from Belcher, P., Sampson H., Thomas M., Veiga J., \& Zhao M. (2003). Women Seafarers: global employment policies and practices. pp 14, table 5 (Women students enrolled in MET institutions in 2001. portion of 6 percent on cargo ships.

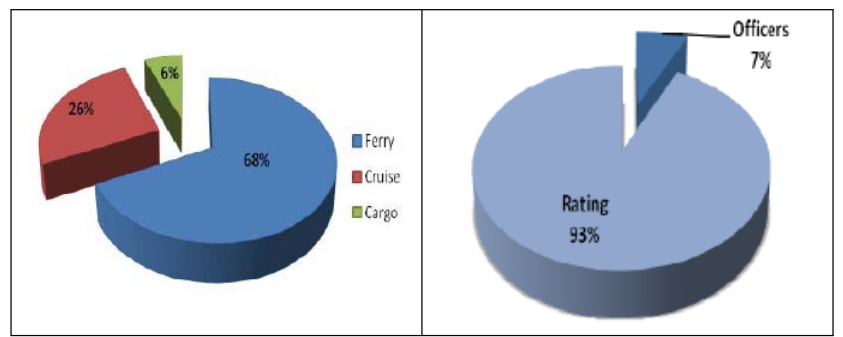

Fig. 1 Employment of women by ship type and distribution by rank in the world

\subsection{Current Korean women seafarers' occupation} in the global merchant ship market

The author found2) many major shipping companies where women have been present and identified as shown below in Table 2, where roughly 50 are women. Table 2 lists a sample of the companies that employ women in merchant fleets. Furthermore, it identifies the proportion of women seafarers in 1.96 percent against the total of Korean seafarer officers in A-I shipping companies.

Table 2 Women seafarers employed in shipping companies3), '10

\begin{tabular}{|c|l|c|c|c|c|}
\hline & \multicolumn{1}{|c|}{ Description } & $\begin{array}{c}\text { Total No. } \\
\text { of fleets }\end{array}$ & $\begin{array}{c}\text { Total } \\
\text { Korean } \\
\text { officer }\end{array}$ & $\begin{array}{c}\text { Women } \\
\text { seafarers } \\
\text { (officer) }\end{array}$ & $\%$ \\
\hline A & Foreign Flag vessels & 47 & 211 & 0 & 0 \\
\hline B & Foreign Flag vessels & 77 & 232 & 0 & 0 \\
\hline C & Foreign Flag vessels & 65 & 248 & 4 & 1.6 \\
\hline D & Foreign Flag vessels & 56 & 275 & 0 & 0 \\
\hline E & Foreign Flag vessels & 88 & 543 & 0 & 0 \\
\hline F & $\begin{array}{l}\text { Ocean going } \\
\text { Korean Flag }\end{array}$ & 31 & 201 & 10 & 5.0 \\
\hline G & $\begin{array}{l}\text { Ocean going } \\
\text { Korean Flag }\end{array}$ & 43 & 312 & 10 & 3.2 \\
\hline H & $\begin{array}{l}\text { Ocean going Korean } \\
\text { Flag+Foreign Flag }\end{array}$ & 102 & 540 & 18 & 3.3 \\
\hline I & $\begin{array}{l}\text { Ocean going } \\
\text { Korean Flag }\end{array}$ & 79 & 498 & 8 & 1.6 \\
\hline \multicolumn{2}{|c|}{ Total } & 455 & 2553 & 50 & 1.96 \\
\hline
\end{tabular}

Source : survey by Sohyun Jo, based on Korea Seafarer's Welfare \& Employment Center, ship and crew research, 2010

2) The author surveyed major Korean shipping companies registered in various parts of the world, through telephone interviews with responsible human resource managers or seafarer manning managers during 21-24 June, 2010. The author selected major shipping companies which most of the graduated maritime university students apply have applied in.

3) Among ocean going Korean Flag and Foreign Flag vessels, collected and listed the companies that have more than 200 in the total number of officers. 
The research found that the total number of ships in Korean shipping companies including ocean going Korea Flag and Foreign Flag vessels, are 2,226 ships, and Korean officers are 9,452 officers. Amongst the total of 9,452 officers on cargo fleets in Korea, the shipping companies employed 50 women seafarers, 0.52 percent of the total number of Korean seafarers.

\section{Survey}

\subsection{Background to the survey questionnaire}

Women seafarers in this study are understood to be those who work in cargo ship, for example, the navigation and engine departments. During research in 2010, 26 women current and former seafarers from Korea were successfully contacted with a response rate of 68 percent. Of these, 26 women participated in the survey which through telephone and questions, in-depth interviews were used as the major means of research according to individual participant preference. Although the response of questionnaires and data were only collected from a limited number of seafarers, these individuals were carefully selected with the view of considerable experience at sea.

However this questionnaire contents focus upon women seafarers' problems and concerns regarding employment on cargo ships such as problem with colleagues, difficulty to retain why and how deal with these problems, the areas to be improved and also shipping company responsibility as follow paragraphs.

\subsection{Response details}

As Table 3, shows the rate of distribution of the respondent group's age, the current occupation, type of ship and career onboard ship. The majority of respondents are of the an average age between 30 and 35 years. In addition, the majority of women in this research have experience on bulk carriers and container work. However, it is noted that the respondents from gas carriers were cadets, not officers. Actually, there is no record as yet of any history of as Officers or Engineers on oil tanker ships and gas carriers.

The author questioned these comments with a human resource manager in a tanker shipping company, and he stated,

"There is no particular reason, we do not think there is a taboo against women. When we hire employees, we should consider who would make an adequate employee in our company the same as for other shipping companies, it should follow quality and the internal system, not be influenced by any particular issues."

Other tanker shipping company managers stated regarding the employment of women officers in an interview that:

"We feel sorry about the lack of proactive employment of women, but it is true that the tanker shipping world has a conservative view of women. In fact, the ship area of the tanker industry retains conventional views. This point of view may be because they have to handle a dangerous cargo at all times, the responsible crew members could be more sensitive with a woman. That woman onboard is a taboo in the shipping world as it might cause a serious disasters or accidents."

Table 3 Response details

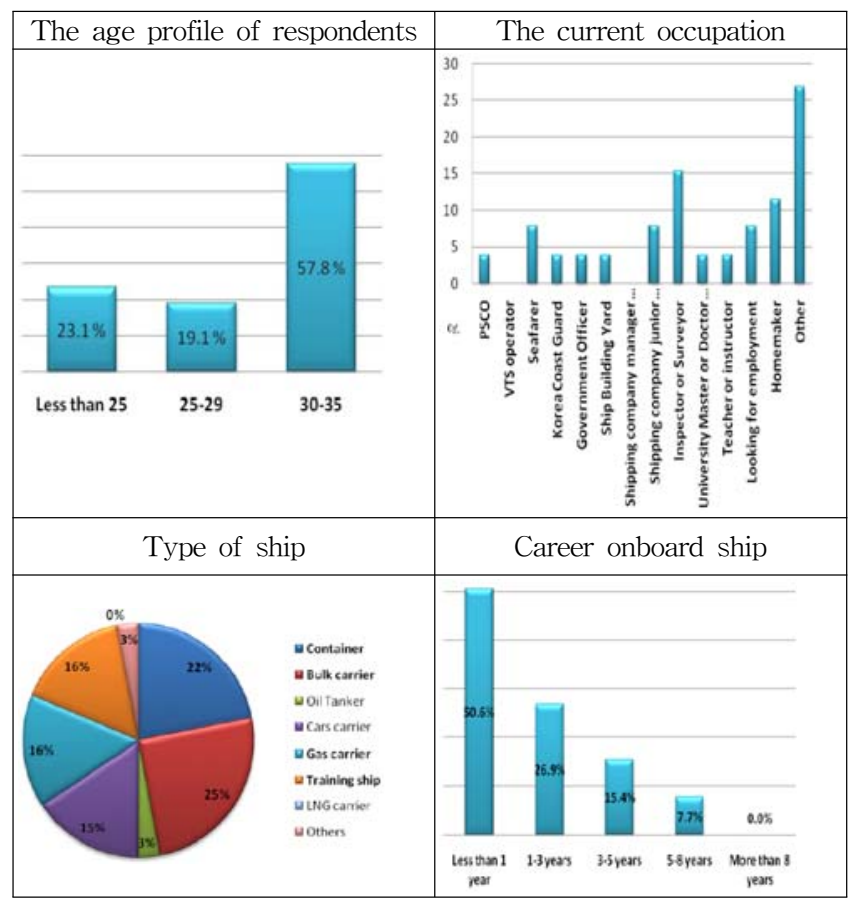

Source : Survey by Jo S.H. 2010

However, many shipping companies have been considering a friendlier and a safer safety atmosphere. For example, the $\mathrm{S}$ shipping company tries to place women exclusively on new ships on long haul and on older ships on short-sea voyages. Other shipping companies have placed women officers onboard container ships mostly because they appreciate their meticulousness and detailed performance as well as it being a more acceptable living environment on ships. The shipping companies examined that many women officers on container ships have carried out their performance satisfactorily and with remarkable ability more so than their male colleagues(Kim, 2008). 


\subsection{Key data from women seafarers}

1) Main motivation of selecting to be a seafarer

Women are attracted to work at sea for various reasons. Figure 2 demonstrates there reasons for choosing a seafaring career. The highest response shows a desire to work at sea, with 54 percent of respondents.

In comparison, in the cruise sector, women from developing countries respond to the potential earning opportunity compared to lesser economic opportunities from shore-based jobs(Belcher et al., 2003, Zhao, 2001). This further explains why most Asian women primarily focus on the financial advantages of seafaring.

On the contrary, women from developed countries cite the opportunity to travel and "see the world for free" as the most significant motivating factor to join the cruise sector; (Belcher et al., 2003) and they were seemingly less motivated by economic reasons such that most developed countries women seafarers noted that "money is not my major concern.(Zhao, 2001).

Once again the respondents recount a major motivating reason for choosing seafaring in Korea that is to examine one's self, satisfies own desire for a different environment

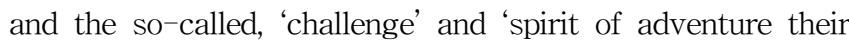
own way'. Initially, it indicates that Korean women desire to be more adventurous and thus go seafaring around the world.

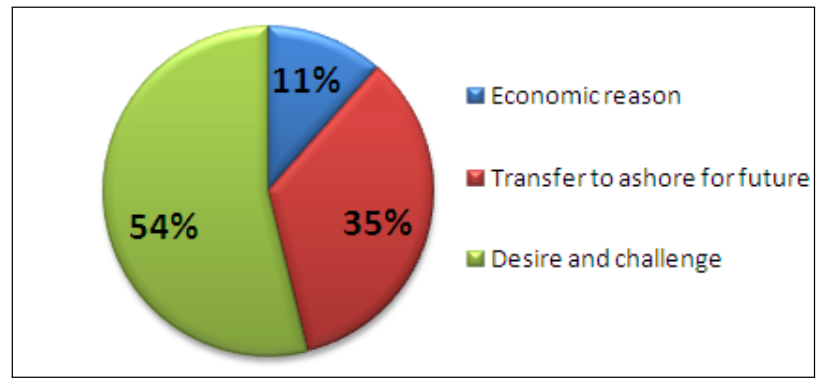

Source : Survey by Jo S.H. 2010

Fig. 2 Main motivation to select a seafaring job

\section{2) Experience of facing problems with colleagues}

Nearly 32 percent of all respondents had have experience of sexual discrimination with colleagues at sea, as highlighted in Figure 3. Only 13 percent of respondents have in fact not experienced any problems with colleagues. However, the combined similar question with 'Sexual discrimination', 'Sexual harassment' and 'Non sexual harassment' is a higher rate at 50 percent than 16 percent of 'Intentional ignorance', 13 percent of 'None' and zero percent of 'Bullying'. It is significant that half of the respondents have experienced problems which are inherently sexual or non-sexual harassment and discrimination.

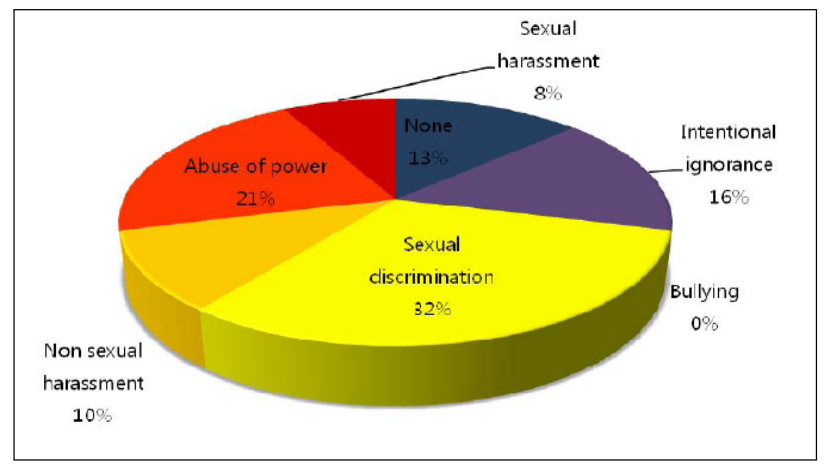

Source : Survey by Jo S.H. 2010

Fig. 3 Experience problem with colleagues

One reported experiences of sexual harassment cases by Belcher et al.(2003) is,

"When I got up to go to the bridge to work, he was lying down on his side, I could see him from my door, he was totally naked and was masturbating. [‥] So it really freaked me out when he turned his head and smiled at me. So I kind of got scared. I started arriving late for my duty watches and I asked my senior officer to come down to escort me up."

One interview with a human resource manager of a shipping company in Korea outlined a recent case of harassment that recently occurred when a female officer came into her cabin after a party with all the crew members ; she could not stop screaming when she found a naked sailor sitting on the edge of her bed in her cabin.

Other stated experience of sexual discrimination case which excessive concern for female officers may have made it more difficult on-board ship. As one ex-seafarer women in Korea stated,

"When I was on a container ship for training, the Captain tried to install another lock to my room door which cannot be opened from the outside once locked. Of course, such a device was against the safety regulations. Such overprotection made me very uneasy. I could not go to a lower deck because I was a woman, and I could not do something, because I was a woman.”

Moreover, for women who faced these problems with colleagues, this research found how they dealt with the problem as indicated in Table 4. It is worth noting how they had overcome or coped with this situation. The 
majority (nearly 35 percent) of respondents reported that they used to keep it to themselves when they experienced a problem with male colleagues.

One female ex-seafarer in Korea stated that when she was interviewed, she remained in the 'keep silent mode',

"I have never been taught how to handle maltreatment or sexual harassment of students by taking advantage of performance ratings. I believe that there have been many similar cases which have been covered because such issues may cause trouble for all female officers."

Eventually, based on the above data, the results demonstrated that women behave by keeping problems to themselves or share emotional distress with someone close to them, rather than reporting the incident to senior officers or the company. It seems that women have a passive attitude to taking up issues rather than active attitude such as to report it to the company or seafarers unions.

Table 4 How deal with problem

\begin{tabular}{|l|c|}
\hline \multicolumn{1}{|c|}{ How deal with problem } & $\begin{array}{c}\text { Frequency } \\
\text { (\%) }\end{array}$ \\
\hline Keep it to oneself & 34.9 \\
\hline Share it with family and/or friends & 7.7 \\
\hline Share it with colleagues and get support from them & 30.8 \\
\hline $\begin{array}{l}\text { Report it to your senior (ie, Captain, chief officer, } \\
\text { chief engineer, etc) }\end{array}$ & 23.1 \\
\hline Report it to company's manager & 0.0 \\
\hline Report it to Seafarers Union & 0.0 \\
\hline Other & 3.8 \\
\hline Total & 100.0 \\
\hline
\end{tabular}

Source : Survey by Jo S.H. 2010

3) The difficulty to retain women at sea

Nearly 27 percent of all women respondents recognize the biggest difficulty onboard is the loneliness and isolation from family and closer friends as indicated in Table 5. This is absolutely the worst aspect for all seafarers working at sea today, loneliness and living away from family and society, and the difficulties of keeping in touch(Bansal, 2009). The negative impact of isolation from society is a common issue for all seafarers, not only for women(Kitada, 2009b).

In this approach, the majority of women seafarers experience difficulties with the lack of other women onboard to talk and share their feelings. Some women are uncomfortable trying to join a male crew community but also they sometimes feel the need to communicate with someone of the same gender. Often there are feelings of loneliness when there is no one to talk to according to one interview by the journal of Monthly Maritime Korea(Kim, 2008). As one of $\mathrm{ex}^{-}$seafarer Korean woman put it,

"Sometimes I feel lonely having no one to talk to about anything. I think actually there is only one woman with me to talk to about any kind of subjects, I feel more comfortable without loneliness and isolation from the male community. My loneliness was hard to bear.'

Secondly, 23.1 percent of women respondents pointed out that they faced sexual discrimination from male colleagues. One of comments of this survey, many man used to be doubtful of women seafarers ability, for example, man try to find out what female colleagues have done completely well or not. Other comments are that have denied to women applicants work opportunities in the shipping industry, even if the woman's student credentials are higher than those of the male students. As one ex-seafarer woman in Korea stated,

"Actually, most female students have been working harder and superior to male students in terms of GPA. Most companies say that they do not discriminate against female applicants, but most of them recruit only one female applicant. I heard that a major shipping company employs a female applicant for formality's sake or for the company's public image because it is forced to do so. [...] Since I experienced discrimination after graduation and I experienced personally how difficult it is to join a male-oriented organization."

Thirdly, 15.4 percent of women who responded they had a difficulty with the traditional social role for women such as marriage, and nurturing children. Kitada(2009b) stated, in the case of women seafarers, that it is more complicate to keep a balance between their sea lives and maintaining a relationship before marriage. In such a circumstance, consequently, many women weigh the pros and cons in their minds which decision would be better for them, and then, most decide to give up their seafaring career.

According to Ishida(2010), the study describe the conditions of women seafarers in Japan which from the viewpoint of the international and domestic shipping industry. This study investigate that companies raise the high rate of leaving the company for marriage or pregnancy as a reason for the unemployment of women.

In the Korean case, there is no record of the number of women seafarers who have married and continued working onboard in cargo ships. Seafaring requires being onboard for several months, in fact that might not satisfy the social role of mother or women. Thus, the social pressure or 
traditional social responsibility might make her confused when deciding to be away from home or staying at sea when she comes of a marriageable age or before marriage in general(Kitada, 2009b).

As the same 15.4 percent, some women find the work difficult onboard whereas, the routine ships' work seems to be an unsuitable environment for women for instance, irregular ship arrival and departure, being over-worked, the physical hard work, and the hot environment in the engine room.

Table 5 The difficult elements of seafaring at sea

\begin{tabular}{|c|l|c|}
\hline & \multicolumn{1}{|c|}{ The difficult elements of seafaring at sea } & $\begin{array}{c}\text { Frequency } \\
(\%)\end{array}$ \\
\hline 1 & Isolation or loneliness & 26.9 \\
\hline 2 & Sexual discrimination from male colleagues & 23.1 \\
\hline 3 & $\begin{array}{l}\text { Traditional social responsibility for women ; } \\
\text { marriage, nurturing children }\end{array}$ & 15.4 \\
\hline 4 & $\begin{array}{l}\text { Specialty of job and physical difficulties } \\
\text { related to job }\end{array}$ & 15.4 \\
\hline 5 & $\begin{array}{l}\text { Gender inequality; unequal promotion } \\
\text { opportunities }\end{array}$ & 8.0 \\
\hline 6 & other & 11.2 \\
\hline & Total & 100.0 \\
\hline
\end{tabular}

Source : Survey by Jo S.H. 2010

4) Opinion of how to improve working environment

Women seafarers are a minority of entity of seafarers on cargo ships. Women seafarers also transfer shore-based employment more quickly than male seafarers.

Most companies I investigated demanded that women seafarers stay at least three years same as young males who have to fulfill an obligatory three year on board work assignment, while admitting that most women are excellent and motivated when entering the company. Considering this, the responsibility rests with women, because it suggests that women have a weak sense of professionalism.

However, this study would explore why women seafarers decide to go to shore-based job soon and need to find solutions. In order for this situation to improve, this research investigates what areas are needed to create a better environment for women. The results of the question are shown in Table 6.

Table 6 shows a majority of 53.8 percent of the respondents report that there is a need to improve the shipping company's policies and insure greater social responsibility towards women seafarers. Therefore, the author's research examines what changes are needed to provide sufficient support in terms of shipping companies; these are examined in order of priority as follow Table 7.

Table 6 Strategy to improve and develop the working environment

\begin{tabular}{|c|l|c|}
\hline & Top priority of area to improve & $\begin{array}{c}\text { Frequency } \\
(\%)\end{array}$ \\
\hline 1 & $\begin{array}{l}\text { Shipping company's policy and social } \\
\text { responsibility (CSR) }\end{array}$ & 53.8 \\
\hline 2 & \begin{tabular}{l} 
The effort of improvements by self-motivated \\
\hline 3
\end{tabular} & $\begin{array}{l}\text { Korea has a social role and responsibility for } \\
\text { females }\end{array}$ \\
\hline
\end{tabular}

Source : Survey by Jo S.H. 2010

Table 7 Priority elements for improvement of shipping company

\begin{tabular}{|c|l|r|}
\hline & Top priority elements for improvement & $\begin{array}{c}\text { Frequency } \\
(\%)\end{array}$ \\
\hline 1 & Encourage policies to work at sea & 30.8 \\
\hline 2 & $\begin{array}{l}\text { Granting of medical leave for menstrual } \\
\text { period }\end{array}$ & 26.9 \\
\hline 3 & $\begin{array}{l}\text { Consideration of a female group onboard to } \\
\text { support one another }\end{array}$ & 15.4 \\
\hline & $2^{\text {nd }}$ priority elements for improvement & $\begin{array}{c}\text { Frequency } \\
(\%)\end{array}$ \\
\hline 1 & $\begin{array}{l}\text { Pregnancy policy, grantee of maternity leave } \\
\text { and reinstatement } 5 \text { ) }\end{array}$ & 34.6 \\
\hline 2 & Encourage policies to work at sea & 19.2 \\
\hline 3 & $\begin{array}{l}\text { Granting of medical leave for menstrual } \\
\text { period }\end{array}$ \\
\hline
\end{tabular}

Source : Survey by Jo S.H. 2010

5) Other comments from respondents

The study noted other comments from respondent's interviews that the gender inequality and unequal opportunity for women seafarers is often faced when applying for a job or promote in shipping industry. Also respondents indicated the topic of improving the living conditions onboard', however, they recognized it is not only for women, but also for all of seafarers as well as emphasizes the importance of the quality of life at sea. Lastly, they pointed out relatively low social recognition. a case of one of the interviewees from a Korean women ex-seafarer who has experience of less than 2 years onboard a car carrier,

"I said I am an officer on a cargo ship. However, they tried to say something a few seconds later as the majority

4) Included grantee through quality system or document in official way for medical leave for menstrual period as well as establish company culture which can make a smooth progress.

5) Same as above footnote 
of them could not recognize what women officers do on such ships. And then, most of them said, sure,'oh, great! great you' but they looked at me with sympathy. Or others say, 'you are a really strong person more than a man, how is sea life and can you bear the hard work, for example the fishing? Or 'Oh you are so lucky, you are able to eat raw fish easily whenever you want' they said."

It means that most Koreans have preconceptions, misconceptions and stereotypes about 'seafarers' in terms of a merchant ships.

\section{Recommendation}

The top priority for shipping companies should obviously be to regard seafarers as one of the important stakeholder elements in any company, not just a cost element in economic terms(Monthly Maritime Korea, 2008). In shortly, there is needs to be an awareness of seafarers as contributors in accomplishing a high quality seaborne trade service a cross the world, that is qualified professionals who enjoy a rich work experience. Another crucial point is how effectively a manager or decision maker in a shipping company can encourage and instill pride in seafarers. Therefore, current the problems which surround today seafarers will be solved when shipping companies change their perception towards seafarers first of all, not just because they are employees. The author recommends what ultimate strategies need to be created to make a working environment focusing on women seafarers as a priority.

\subsection{Support and motivation to go to sea}

Today, shipping companies should be capable of contributing to the development of a corporate culture in the more proactive and practical way. To achieve the ultimate corporate culture, it must be borne in mind that the key point is to motivate and encourage women seafarers as well as establish a vision of a seafarers job(Hwang, 2008)

Shipping companies are recommended to explore the possibility of a new job-version for the woman seafarer which they would be the best professional career in maritime field as well as they would be a high quality human resources.

Therefore, shipping companies need to take a view a long-term perspective and make a drastic investment(Ibid) in women seafarers within future-oriented thinking. In order to acknowledge how to motive women seafarers within shipping company, this research advocates a more practical approach as described in the following paragraphs of this chapter.

\subsection{Create consideration for equal opportunities}

Definitely, the number of women seafarers is a minority in the shipping industry throughout the world. However it is evident that many women desire to attain a job at sea. Despite the rising numbers of applications for position on board ship in recent years, it has been hard to open an 'employment' door in this competitive job market. It is obvious that there is a diversity of reasons for shipping companies if they hesitate to willingly hire women. However, if they seldom offer the same opportunity, how do women prove they have the qualification and ability to do a seafaring job? The shipping company should establish an employment equality policy and encourage the hiring of women on a similar basis to men(Aggrey, 2000).

\subsection{Training and education for understanding and harmonizing with females}

Many shipping companies seek to create a workplace environment that is inspiring and develops diverse talent in order to carry out the performance of ship operations in an effective way. A key component in this system focuses on improving the ways to verify knowledge and the skill mastery of the ship's crew such as maneuvering, cargo handling, ship handling simulator, job familiar course, support on-the-job training and E-learning.

However, shipping companies need to provide a gender familiarization programme to be harmonized with females. Even the employed seafarers prior to embarkation on ships are provided with familiarization training according to STCW before being assigned to particular duties, which does not involve gender issues.

However, the author would recommend that the most significant thing to understand the gender issues would be a shift in the male seafarer's awareness through the gender familiarization programme. The gender familiarization programmer should contain elements from the basic gender issues of how to create balance and harmony between different genders in the work environment in order to reduce the potential for sexual discrimination against females, cultivate the ship's communal culture, as well as create a gender friendly working environment.

\subsection{Establish a sex harassment policy and control}

As a result of the author's survey and in-depth interviews, it is concluded that many women also reported 
problems with some male colleagues in terms of sexual issues.

The effect of sexual harassment of any form on women onboard ship can be considerable and can have a direct influence on their career whereas the ships' occupational hierarchies concentrates well on their personal well-being (Belcher et al. 2003). Indeed, in order to fully understand the impact of sexual harassment issues of any form on women onboard ship, it is necessary to talk openly, to be open, and to be brave, not just to employers, but also to women seafarers themselves. One objective of this research is to profile sexual harassment on ships so that it can be dealt more effectively.

Special education programmes regarding sexual harassment are commonly conducted in the industry in accordance with national regulations. This education is under the Article 13 of the 'Act on Equal employment and Support for Work-Family Reconciliation' and the 'Framework Act on Women's Development ${ }^{6)}$ '. Under Korean Law, the employer should conduct education to 'Prevent Sexual Harassment in the Workplace 7 ') at least a once year8), in order to prevent sexual harassment in the workplace.

In order to guarantee a safer ship board environment, the author would suggest that shipping companies need to install formal grievance procedures, whereby employees are invited to air their grievances which relate to sex discrimination, sexual harassment or abuse of power and other aspects relating to sexual behavior. It should incorporate disciplinary action measures, follow-up

6) Framework Act on Women's Development adopted 1995, December 30, last amendment on Act number 8852, 2008, February 29 The purpose of this Act is to promote the equality between men and women in all the areas of politics, economy, society and culture and to facilitate the women's development by stipulating the fundamental matters with regard to the obligation, etc. of the State and local governments for realizing an idea of equality between men and women under the Constitution of the Republic of Korea. Source form Article 1(purpose) under the 'Framework Act on Women's Development'

7) Article 13 (Education to Prevent Sexual Harassment in the Workplace) under the 'Act on equal employment and support for work-family reconciliation'; (1) An employer shall conduct education in order to prevent Sexual Harassment in the workplace (hereinafter referred to as the "education to prevent sexual harassment") and to create a safe working environment for workers. (Amended 2007 December, 21)

8) Article 3 (Education to Prevent Sexual Harassment at Work) under the 'Act on equal employment and support for work-family reconciliation'; (1) Employers shall, pursuant to Article 13 of the Act, conduct education on preventing sexual harassment at work at least once a year. (Amended by Presidential Decree No. 19366, Feb. 28, 2006) measures, and assure the confidentiality of employees and identify the designated persons who deal with such enquiries relating to those issues. It should carry out the role as the reception window when women want to report their problems.

\subsection{Establishment of specific policies for women seafarers}

Shipping companies should establish diversified welfare programmes for women such as the granting of medical leave for menstrual periods, pregnancy policy, granting of maternity leave and reinstatement of employment. Such a menstrual leave is stated under the Article 83(Menstruation Holiday9) ) of the 'Act on Seafarers' under Korean Law, where women seafarers are entitled to one day of menstrual leave every month.

However, with a ship's special duty working environment and the rotation of duty time between three duty officers per day, it is not easy to request and receive menstrual leave without adequate notice(Lee, 1999).

The above examples of menstrual leave are far from the present situation in Korea according this research data; however, with in a future-oriented policy, shipping companies should attempt to provide a proactive welfare programme to guarantee women that they would be treated with a better working environment.

Also, the most important message is that it is essential to create a corporate culture in which women can request access to the above programmes without any concerns the companies would not accept such requests.

\subsection{Female working together}

The author's research demonstrates that most women officers feel the impacts of isolation or loneliness as they are the only females on board ship. The majority of women expressed difficulties with the lack of other women onboard to talk to and share their feelings. To solve these problems, the author would suggest that shipping companies should attempt to put more than one woman onboard for voyages of significant periods(Kitada, 2009a; Kim, 2008; Kim, 2008).

The author agrees with Kitada(2009a) who has recommended that to increase the number of women seafarers there is a need to change the mentality and create a better working environment for both men and women.

To put more women together onboard ship may be

9) Article 83 (Menstruation Holiday): The shipowner shall grant a female seafarer one day of menstruation holiday in a month. (Amended 1990 August, 1) 
difficult from practical points of view, nevertheless, it is important that shipping companies attempt to implement the placement of women together on board the same ship.

\section{Conclusion}

Amartya Kumar Sen, an eminent Indian economist who won the Nobel Prize in Economic Science for his contribution to work on welfare economics in 1998, has stated,(Song, 2006):

"Nothing is more important in economic development than women's participation."

Seafarers, have been playing a key human resource role in the maritime industry. Therefore, at this point of time, the employment of seafarers and welfare programmes within shipping companies are significant factors towards encouraging seafarers, as well as shipping companies to view seafarer employment from a long-term perspective and make a greater investment in women as seafarers.

Inter alia, how we could efficiently utilize the female work force in the maritime labor market is a major factor to increase the number of women seafarers. The integration of women in the seafarer career is not possible without support from international organizations and national governments alone or by any individual efforts. Company cooperation is the most crucial factor(Min, 2006) as it creates jobs as well as a better working environment.

The Deputy of TC in IMO, Tansey(2010) in a recent address stated that, women had little chance to do this at present. Obviously, the author further emphasizes stating that, "women seafarers must be expected and they will respond as key actors in the maritime field in the near future.'

\section{Acknowledgements}

This research was part of the results of the dissertation called "Why not women seafarers? - Towards a development strategy for the recruitment and retention of women seafarers in cargo ships with particular reference to the Republic of Korea" for Master degree of the World Maritime University.

\section{References}

[1] Aggrey, H.A.(2000), Women in the maritime industry : A review of female participation, and their role in
Maritime Education and Training (MET) in the $21^{\text {st }}$ Centry.

[2] Bansal, A.K.(2009), "World-wide manning crisis", International Federation of Ship masters's Associations, Annual review, pp. 15-17.

[3] Belcher, P., Sampson H., Thomas M., Veiga J., and Zhao M.(2003), Women Seafarers: global employment policies and practices, Geneva, International Labor Office.

[4] Hwang J.H.(2008), "Consideration for development of seafarers policy in Rep. of Korea", Monthly Maritime Korea. Vo. 10, pp. 50-53.

[5] Ishida Y.(2010), The conditions of Women seafarers in Japan : from the viewpoint of the International and Domestic shipping industry, WISTA annual conference.

[6] International Labour Organization(2007), Gender equality around the world : Women seafarers fighting against the tide? Geneva : International Labor Office.

[7] Kim E. M.(2008), Mokpo Maritime University, allow a progressive in creasing women student and accepted recommend action of National Human Rights Commission of Korea. Newsis. Retrieved June 10, 2010 from the World Wide Web : http://news.naver.com

[8] Kim C.H.(2008), "Korea Maritime University, more important to development welfare than high salary", Monthly Maritime Korea, Vol.10, pp. 60-69

[9] Kim, K.M.(2008), "Ship, there is no some one to talk to", Monthly Maritime Korea, Vol.1, pp. 80-88.

[10] Kitada, M.(2009a), Risking marriage and family: Maintaining women sefarers's gender identities, The $1^{\text {st }}$ SIRC-Nippon fellow maritime conference, Seafarers International Research Centre.

[11] Kitada, M.(2009b), "The double roles of the female seafarer", Shipgaz, Vol.5, pp.17-19.

[12] Min M.S.(2006), Strategies and action plans for creating jobs for women of Korea : Korea's challenge and strategy for utilization of female work force. International Conference on Job Creation for Women. Seoul, Korea:Minister of Gender Equality and Family.

[13] Monthly Maritime Korea(2008), "Solve the seafarer's problem: first of all, let corporate and government do together for 'secure seafarers' of seafarers investment", Monthly Maritime Korea, Vol.10, pp. 27-46.

[14] Lee Y.C.(1999), "A study on the reasonable protective system for female officers as seafarers", Ocean Industry Research Institute, Korea Maritime, Vol.9, pp.5-35 
[15] Song, W.S.(2006), International Conference on Job Creation for Women. Seoul, Korea, Minister of Gender Equality and Family.

[16] Tansey P.(2010), Women on board - ten years of the IMO Women in Development programme(2000). Retrieved June 15, 2010 from the World Wide Web : http://www.imo.org

[17] Zhao, M.(2001), "Globalisation and Women's Employment on Cruise Ships", Maritime Review, 2001(1sthalf), pp. 77-82.

Received 14 February 2011

Revised 18 March 2011

Accepted 21 March 2011 